Supplementary Information for:

\title{
Quantitative determination of carbonaceous particle mixing state in Paris using single particle mass spectrometer and aerosol mass spectrometer measurements
}

Robert M. Healy ${ }^{1,2}$, Jean Sciare ${ }^{3}$, Laurent Poulain ${ }^{4}$, Monica Crippa $^{5}$, Alfred Wiedensohler ${ }^{4}$, Andre S. H. Prévôt ${ }^{5}$, Roland Sarda-Estève ${ }^{3}$, Maygan L. McGuire ${ }^{2}$, Cheol-Heon Jeong ${ }^{2}$, Eoin McGillicuddy $^{1}$, Ian P. O’Connor ${ }^{1}$, John R. Sodeau ${ }^{1}$, Greg J. Evans ${ }^{2}$, John C. Wenger ${ }^{1}$

${ }^{1}$ Department of Chemistry and Environmental Research Institute, University College Cork, Ireland

${ }^{2}$ Southern Ontario Centre for Atmospheric Aerosol Research, University of Toronto, 200 College Street, Toronto, Ontario, Canada

${ }^{3}$ LSCE, Laboratoire des Sciences du Climat et de l'Environnement, CEA-CNRS-UVSQ, Gifsur-Yvette, France

${ }^{4}$ Leibniz Institute for Tropospheric Research, Leipzig, Germany

${ }^{5}$ Laboratory of Atmospheric Chemistry, Paul Scherrer Institute, PSI Villigen, 5232, Switzerland

Corresponding author email address:

robert.healy@utoronto.ca 

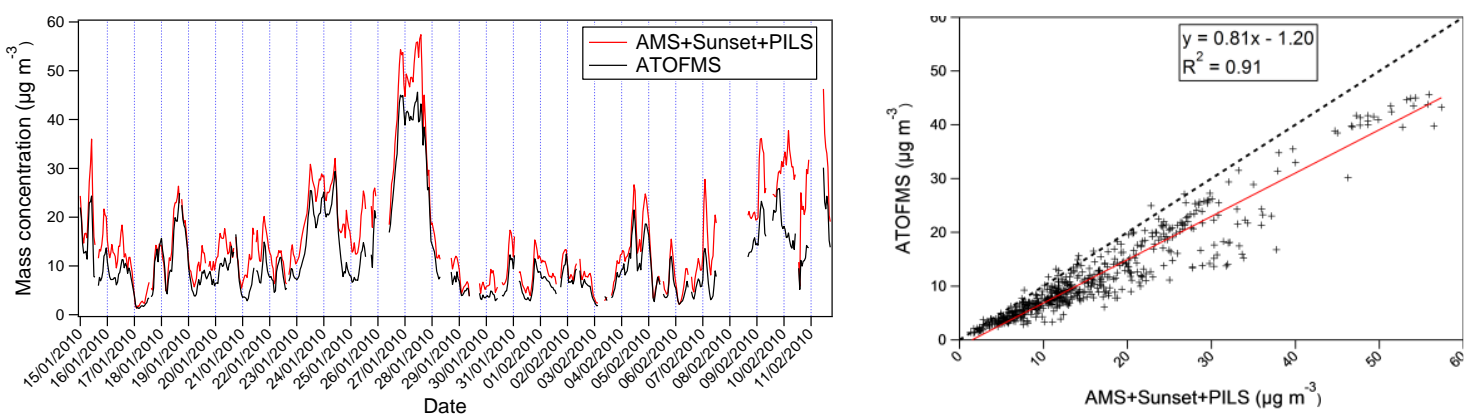

Fig. S1: Temporal trends and correlation for the summed mass concentration of all ten ATOFMS carbonaceous classes and the summed mass concentration of EC, OA, ammonium, sulphate, nitrate, chloride, potassium and sodium measured by the Sunset OCEC analyser, the HR-ToF-AMS and the PILS. The red line represents the orthogonal distance regression fit and the dashed black line represents a 1:1 fit.

\section{S2: Relative sensitivity factors}

A single relative sensitivity factor (RSF) for each chemical species was determined by dividing its average mass concentration (for the entire four week period) by the summed relative peak area of the marker ions for that species observed in the average ATOFMS mass spectrum of the whole dataset (Fig. S2). Thus, the relative sensitivity of the ATOFMS for each species by mass was estimated. 


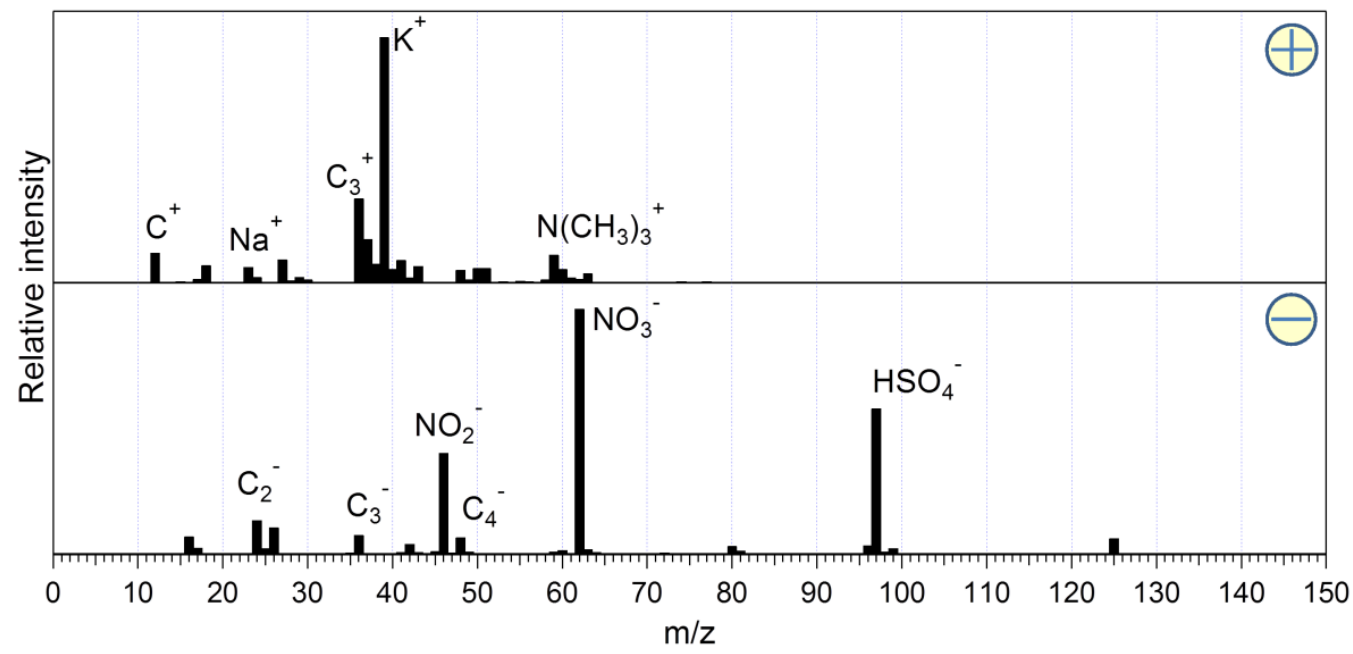

Fig. S2: Number-weighted average mass spectrum of the 1.50 million carbonaceous single particles used to obtain relative sensitivity factors for the six species quantified.

The resulting relative sensitivity factors are shown in Table S1. The units are arbitrary, and all values are given relative to potassium. Smaller values indicate that the ATOFMS has higher sensitivity for those species. It is also important to note that the RSF value for elemental carbon (EC) and organic aerosol (OA) will change depending on the number of marker ions chosen for the calculation.

Table S1: Relative sensitivity factor (RSF) values for each chemical species used for estimating mass concentrations.

\begin{tabular}{|l|l|l|l|l|l|l|}
\hline Species & $\mathrm{K}$ & $\mathrm{EC}$ & $\mathrm{SO}_{4}$ & $\mathrm{NO}_{3}$ & $\mathrm{OA}$ & $\mathrm{NH}_{4}$ \\
\hline RSF & 1 & 29 & 54 & 58 & 284 & 456 \\
\hline
\end{tabular}




\section{S2: Sensitivity analysis using seven day subsets of the ATOFMS dataset}

The suitability of the ATOFMS quantification approach to predict the variability and mass concentrations of the six chemical species was tested by selecting seven day subsets of the four week dataset, and comparing these to the average mass concentrations measured by the HR-ToF-AMS, Sunset and PILS instruments for the same period. The relative sensitivity factors (RSFs) obtained were then used to predict mass concentrations of each species for all four weeks. The variability of each species was reproduced very well despite the subset chosen, as shown in Table S2. However, the slopes were observed to vary significantly depending on the subset. This can be explained by examining the classes that are prevalent during each seven day period. The subset from week 2, for example, produces reconstructed mass concentrations for each species that are most similar to those produced by the full dataset, with the exception of potassium. This week (22/01/2010-29/01/2010) was influenced by both marine and continental air masses, and thus all ten mixing states are well represented in the average mass spectrum generated. Conversely, a much greater divergence is observed when using the subset from week $3(29 / 01 / 2010-05 / 02 / 2010)$, because this period was influenced almost exclusively by marine air masses and the single particle classes associated with continental transport have minimal contribution to the average mass spectrum generated. Thus, the quantification approach described here is expected to be most accurate when the dataset used for prediction is as large as possible, encompassing differences in mixing state that occur due to changes in meteorology and air mass origin. Thick secondary coatings have been demonstrated to affect RSF values for internally mixed species detected by ATOFMS (Pratt and Prather, 2009), therefore RSFs are expected to vary significantly depending upon season and receptor site location. 
Table S2: Comparison of ATOFMS-derived, HR-ToF-AMS, PILS and Sunset mass concentrations for OA, EC and inorganic ions derived using seven day subsets. Results for the full ATOFMS dataset are also included for comparison.

\begin{tabular}{|l|l|l|l|l|l|l|l|l|l|l|l|l|}
\hline Species & \multicolumn{2}{l}{$\mathrm{SO}_{4}$} & \multicolumn{2}{l}{$\mathrm{NO}_{3}$} & \multicolumn{2}{l|}{$\mathrm{NH}_{4}$} & \multicolumn{2}{l|}{$\mathrm{OA}$} & \multicolumn{2}{l|}{$\mathrm{EC}$} & \multicolumn{2}{l|}{$\mathrm{K}$} \\
\hline & $\mathrm{R}^{2}$ & slope & $\mathrm{R}^{2}$ & slope & $\mathrm{R}^{2}$ & slope & $\mathrm{R}^{2}$ & slope & $\mathrm{R}^{2}$ & slope & $\mathrm{R}^{2}$ & slope \\
\hline Week 1 & 0.78 & 0.58 & 0.67 & 0.70 & 0.78 & 0.76 & 0.75 & 1.25 & 0.71 & 1.49 & 0.78 & 0.64 \\
\hline Week 2 & 0.79 & 0.75 & 0.68 & 0.81 & 0.80 & 0.71 & 0.75 & 1.10 & 0.75 & 1.17 & 0.78 & 1.27 \\
\hline Week 3 & 0.79 & 0.50 & 0.67 & 0.50 & 0.81 & 0.70 & 0.75 & 1.54 & 0.73 & 1.54 & 0.79 & 0.65 \\
\hline Week 4 & 0.78 & 0.88 & 0.68 & 0.93 & 0.81 & 0.96 & 0.77 & 0.89 & 0.75 & 0.72 & 0.77 & 0.66 \\
\hline All data & 0.78 & 0.66 & 0.67 & 0.78 & 0.78 & 0.82 & 0.75 & 1.16 & 0.72 & 1.14 & 0.78 & 0.76 \\
\hline
\end{tabular}




\section{S3: Effect of scaling upon relative contributions of each particle class}

A single mass-weighted average mass spectrum generated from the 10 classes was expected to give a more representative contribution of each class to $\mathrm{PM}_{0.15-1}$ for the measurement period. However, the average mass spectrum obtained was almost identical to that obtained using a number-weighted average (Fig. S2). This can be explained by the similarity of the relative contributions shown in Fig. S3.
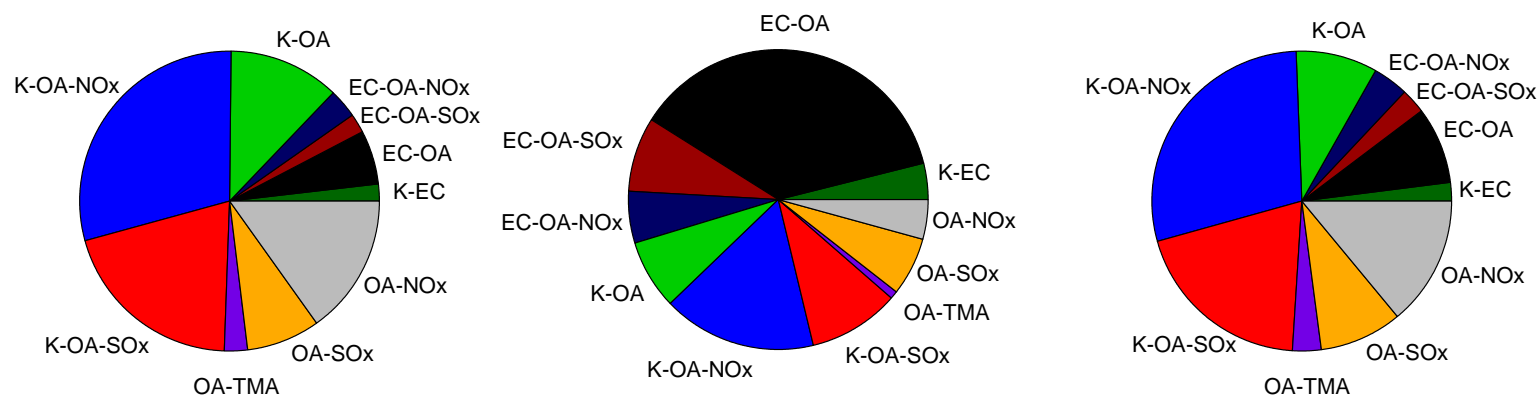

Fig. S3: Relative unscaled particle number (left), scaled particle number (middle) and scaled particle mass concentration (right) for the 10 carbonaceous ATOFMS particle classes.

When the ATOFMS particle counts are scaled to account for size-dependent detection efficiency, the relative number concentrations of the smaller EC-rich particles increases significantly. However, once these scaled number concentrations are converted to volume and mass concentrations, the relative contribution of the smaller particles decreases, approaching the original ratios. It is important to note that this may not be the case for ATOFMS studies performed in locations impacted significantly by larger crustal or sea salt particles, but these findings are encouraging for urban ATOFMS source apportionment studies where scaling ATOFMS particle number concentration data is not an option. Using the mass-weighted average mass spectrum for the quantification procedure gave results that 
were highly similar to those obtained using the number-weighted average mass spectrum, as shown in Table $\mathrm{S} 3$.

Table S3: Comparison of ATOFMS-derived, HR-ToF-AMS, PILS and Sunset mass concentrations for OA, EC and inorganic ions derived using a number-weighted and massweighted average mass spectrum.

\begin{tabular}{|l|l|l|l|l|l|l|l|l|l|l|l|l|}
\hline Species & \multicolumn{2}{l|}{$\mathrm{SO}_{4}$} & \multicolumn{2}{l}{$\mathrm{NO}_{3}$} & \multicolumn{2}{l|}{$\mathrm{NH}_{4}$} & \multicolumn{2}{l|}{$\mathrm{OA}$} & \multicolumn{2}{l|}{$\mathrm{EC}$} & \multicolumn{2}{l|}{$\mathrm{K}$} \\
\hline & $\mathrm{R}^{2}$ & slope & $\mathrm{R}^{2}$ & slope & $\mathrm{R}^{2}$ & slope & $\mathrm{R}^{2}$ & slope & $\mathrm{R}^{2}$ & slope & $\mathrm{R}^{2}$ & slope \\
\hline Number & 0.78 & 0.66 & 0.67 & 0.78 & 0.78 & 0.82 & 0.75 & 1.16 & 0.72 & 1.14 & 0.78 & 0.76 \\
\hline Mass & 0.78 & 0.65 & 0.67 & 0.81 & 0.78 & 0.83 & 0.75 & 1.16 & 0.72 & 1.03 & 0.77 & 0.83 \\
\hline
\end{tabular}




\section{S4: Carbonaceous ATOFMS classes}

Ten carbonaceous single particle classes were identified and quantified using the ATOFMS scaling procedure. Four of these classes have been discussed in detail previously (Healy et al., 2012). The relative number contribution of all ten classes with respect to time and particle size are provided in Figs. S4 and S5, respectively. Number-size distributions for the ten carbonaceous classes are given in Fig. S6. Diurnal and temporal trends for the mass concentration estimates of these classes are provided in Figs. S7 and S8 respectively.

$K-O A$

K-OA particles exhibited a strong diurnal trend, with higher mass concentrations consistently observed in the evening, as shown in Fig. S7. Similar diurnal behaviour was previously observed for the K-EC class (Healy et al., 2012). An intense base peak for potassium $[\mathrm{K}]^{+}$ dominates the positive ion mass spectrum for K-OA particles while a strong signal is also observed for the $[\mathrm{CN}]^{-}$adduct (Fig. 5). The relative intensities for internally mixed nitrate $\left[\mathrm{NO}_{3}\right]^{-}$and sulphate $\left[\mathrm{HSO}_{4}\right]^{-}$are lower than those observed for the other OA classes. The strong diurnal behaviour and relatively small number size mode $(280 \mathrm{~nm})$ suggests that these particles are fresh (Figs. S6 and S7), while the relatively high potassium content indicates that local biomass burning represents the most likely source (Silva et al., 1999; Bente et al., 2008; Healy et al., 2010; McGuire et al., 2011; Harrison et al., 2012; Pagels et al., 2013). Similar mass spectra have also been observed for particles detected in a fresh prescribed biomass burning plume in Wyoming, although additional peaks were observed for potassium chloride and potassium sulphate in that case (Pratt et al., 2011). Similar diurnal behaviour was observed for the primary BBOA PMF factor apportioned to local domestic biomass burning derived from the HR-ToF-AMS data at the LHVP site (Crippa et al., 2013), and comparisons 
are discussed below. There is no obvious dependence upon air mass origin for this class, as expected for a diffuse local source (Fig. S8).

$K-O A-N O x$

K-OA-NOx particles exhibit similar positive ion mass spectra to K-OA particles, but with an additional peak corresponding to ammonium $\left[\mathrm{NH}_{4}\right]^{+}$, and much higher relative peak intensity for nitrate $\left[\mathrm{NO}_{3}\right]^{-}$in the negative ion mode (Fig. 5). The number-size mode of this class is larger than fresh K-OA particles $(310 \mathrm{~nm})$, indicating that K-OA-NOx may represent aged biomass burning particles that have accumulated nitrate during transport (Fig. S6). Similar particles have been detected in Cork City, Ireland, a location dominated by primary local emissions, but were observed exclusively under low wind speed conditions, when local processing was favourable (Healy et al., 2010). In that case, a strong diurnal trend was observed, consistent with condensation of ammonium nitrate on local biomass burning particles. The smooth diurnal trend observed for Paris (Fig. S7) supports the importance of regional contributions of aged biomass burning organic aerosol and nitrate (Crippa et al., 2013). The highest concentrations for this particle class were observed during a regional stagnation event on 23-24/01/2010 (Fig. S8).

K-OA-SOx

The average K-OA-SOx mass spectrum is similar to that observed for K-OA-NOx but with higher signals for ammonium and sulphate. The number-size mode for this class is also similar, albeit slightly larger $(325 \mathrm{~nm})$. This class may thus represent aged biomass burning particles that have accumulated ammonium nitrate and sulphate, and potentially SOA during transport. In contrast to K-OA-NOx particles, the highest concentrations for K-OA-SOx particles are observed during continental transport events, for example on the 26-27/01/2010 (Fig. S8). Elevated sulphate concentrations in Paris have previously been associated with 
advection of emissions from Eastern and Northwestern Europe (Bressi et al., 2012). Interestingly however, elevated concentrations $\left(>5 \mu \mathrm{g} \mathrm{m}^{-3}\right)$ of K-OA-SOx particles are also observed during a low wind speed fog event on 18/01/2010 (Fig. S8). The latter observation indicates that oxidation of $\mathrm{SO}_{2}$ to form particle phase sulphate can occur on biomass burning particles at a local scale in Paris under low wind speed and high relative humidity conditions.

$O A-N O x$

OA-NOx particles do not exhibit a strong signal for potassium and are characterised instead by a positive ion base peak at $\mathrm{m} / \mathrm{z} 36\left[\mathrm{C}_{3}\right]^{+}$, suggesting that these particles do not originate from biomass combustion, but are instead associated either with fossil fuel combustion or SOA formation. Negative ion mass spectra are dominated by nitrate $\left[\mathrm{NO}_{3}\right]^{-}$(Fig. 5), and this class exhibits a similar temporal trend to that observed for K-OA-NOx (Fig. S7), suggesting regional scale contributions. Similar particles have been observed in several urban locations and are typically identified as SOA or aged organic aerosol internally mixed with nitrate (Moffet et al., 2008; Qin et al., 2012). These particles are characterised by a broad size distribution with a relatively large number-size mode at $420 \mathrm{~nm}$ (Fig. S6), and do not exhibit an obvious diurnal trend (Fig. S7).

$O A-S O x$

This class is characterised by mass spectra that are quite similar to OA-NOx, but with lower signals for nitrate $\left[\mathrm{NO}_{3}\right]^{-}$and higher signals for sulphate $\left[\mathrm{HSO}_{4}\right]^{-}$. These particles are much smaller $(255 \mathrm{~nm})$ than OA-NOx particles, and have a significant contribution during the local fog event on 18/01/2010, similar to that observed for K-OA-SOx particles (Fig. S8). The diurnal trend is quite smooth (Fig. S7), and elevated concentrations are observed during periods influenced by continental air masses. Similar particles are routinely observed in ATOFMS field studies, and assigned as SOA or aged organic aerosol that has become 
internally mixed with sulphate through atmospheric processing (Moffet et al., 2008; Cahill et al., 2012; Qin et al., 2012). It is not possible to determine whether the OA-NOx and OA-SOx particle classes represent SOA that has condensed on pre-existing inorganic particles during transport or SOA that has accumulated inorganic ions during transport.

OA-TMA

This particle class is unique in that it is observed exclusively during continental transport events (Fig. S8). The dual ion mass spectra for OA-TMA particles are similar to those

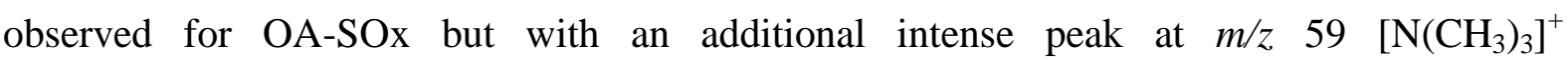
corresponding to trimethylamine (TMA) (Fig. 5). This species has been previously identified in single particles detected in Riverside, CA and Toronto, ON (Angelino et al., 2001; Rehbein et al., 2011; McGuire et al., 2011). In the latter case, elevated levels of internally mixed TMA were observed only when relative humidity was high (>90\%) and air masses arriving at the receptor site had passed over agricultural areas associated with intensive animal husbandry activities. In the case of this work, OA-TMA particles were not observed during a local fog event on 18/01/2010, indicating that local sources of TMA in Paris were negligible (Fig. S8). OA-TMA particles were instead observed during continental transport events characterised by comparatively lower average relative humidity $(76 \%)$. These particles are tentatively assigned as internal mixtures of SOA, ammonium nitrate and sulfate that have undergone heterogeneous reaction with gas phase TMA to form iminium salts during transport over agricultural areas before arrival in Paris (Pratt et al., 2009). The absence of concurrent measurements of particulate phase TMA mass concentrations precluded the quantification of this species using ATOFMS data. The relatively large number-size mode for this class (435 nm) (Fig. S6), and the air mass retroplumes for the corresponding continental transport periods (Healy et al., 2012), both suggest that these particles are significantly aged. Potential source regions for transported particles are discussed in section 3.4. 


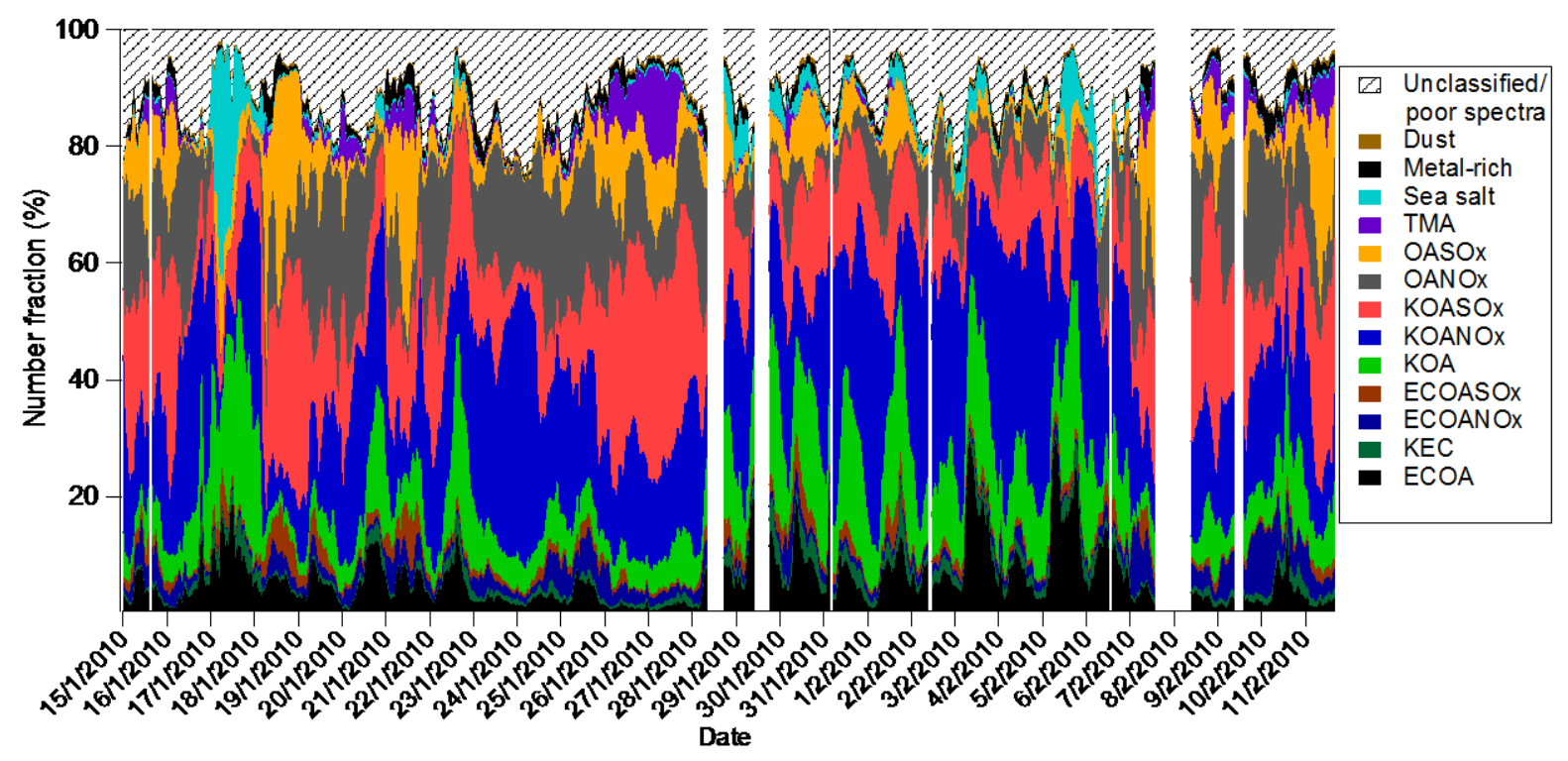

Fig S4: Raw relative number fraction of each carbonaceous particle class detected by the ATOFMS for each hour of the campaign. Unclassified/poor quality spectra, metal-containing, dust and sea salt particles detected by the ATOFMS are also included for comparison. 


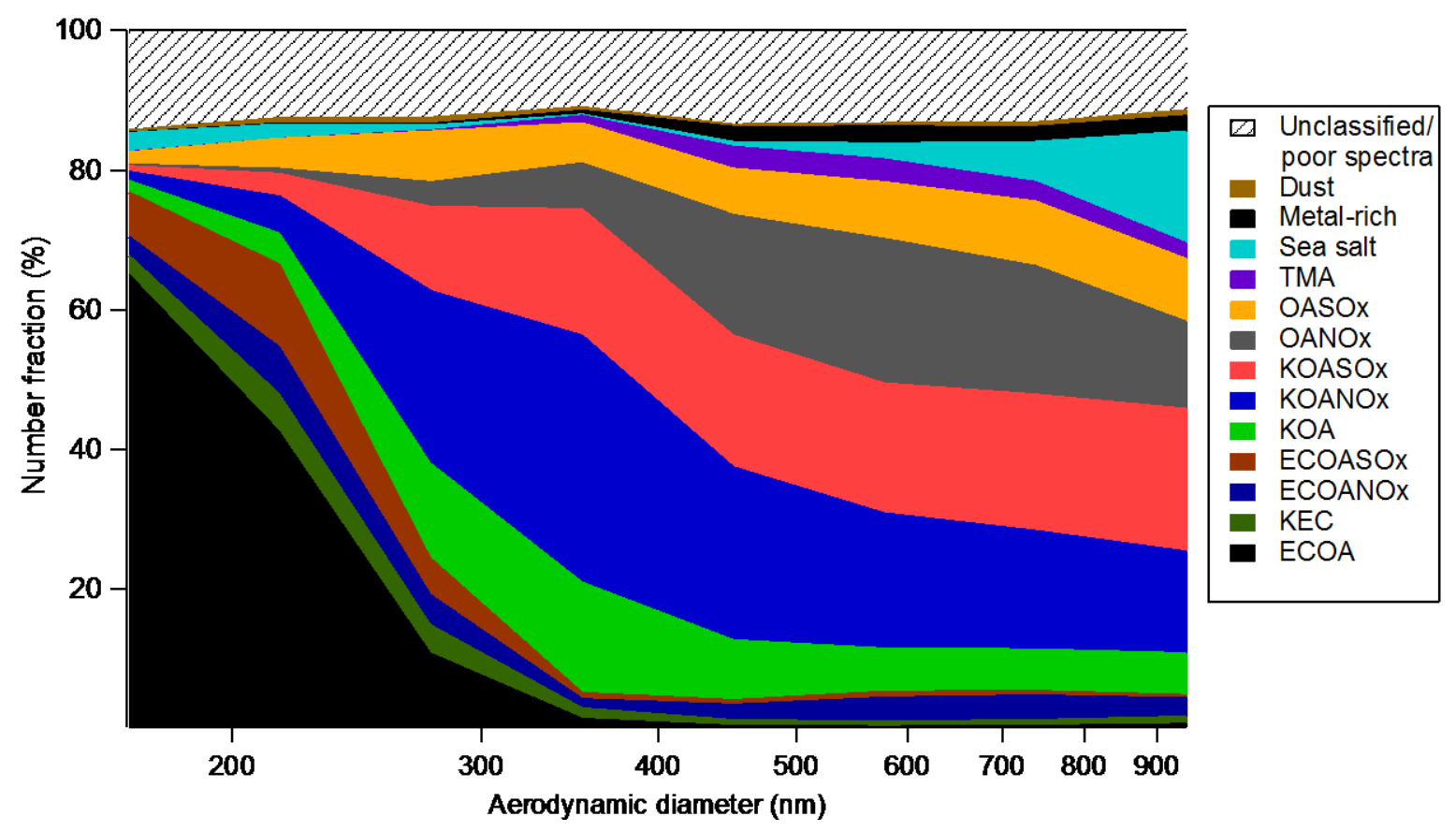

Fig S5: Raw relative number fraction of each ATOFMS particle class as a function of particle diameter. Unclassified/poor quality spectra, metal-containing, dust and sea salt particles detected by the ATOFMS are also included for comparison. 

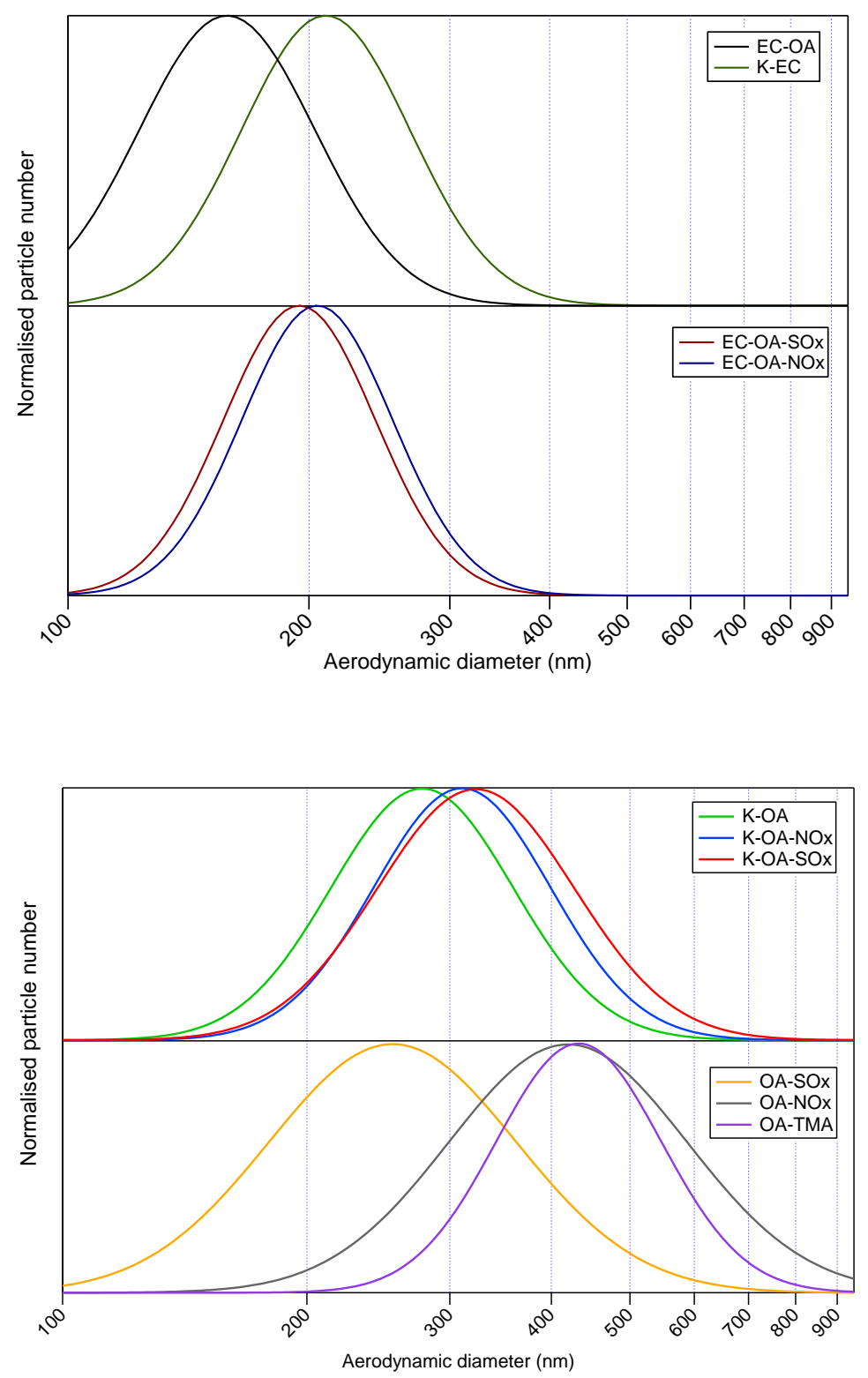

Fig. S6: Average number-size distributions for the 10 ATOFMS carbonaceous classes. Number-size distributions are represented as normalised lognormal fits of the scaled counts in each size bin. The four "EC" classes were described in detail in Healy et al. (2012), but K-EC and EC-OA were termed 'ECbiomass' and 'ECtraffic' in that manuscript, respectively. The estimated average number-size modes for EC-OA, K-EC, EC-OA-SOx and EC-OA-NOx are $158,210,195$ and $205 \mathrm{~nm}$, respectively $\left(d_{a}\right)$. 

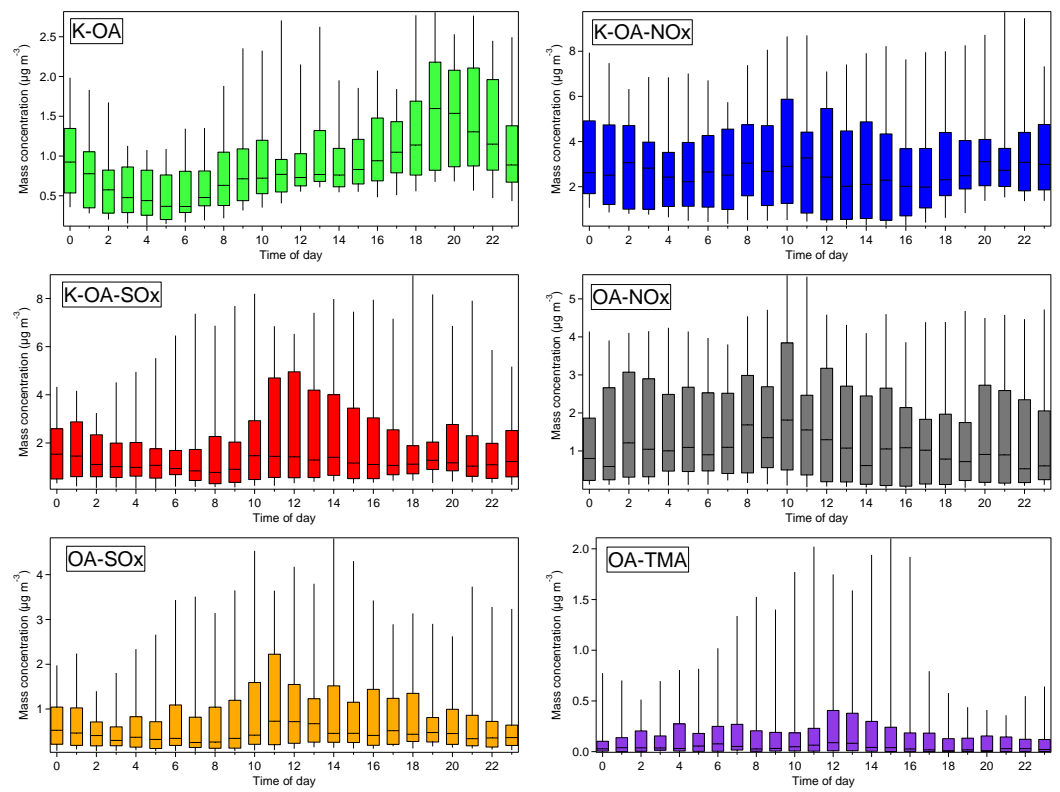

Fig. S7. Diurnal trends of estimated mass concentrations for the ATOFMS OA particle classes $(\mathrm{N}=27)$. Median, $75^{\text {th }}$ percentile and $90^{\text {th }}$ percentile are denoted by the solid line, box and whisker respectively.

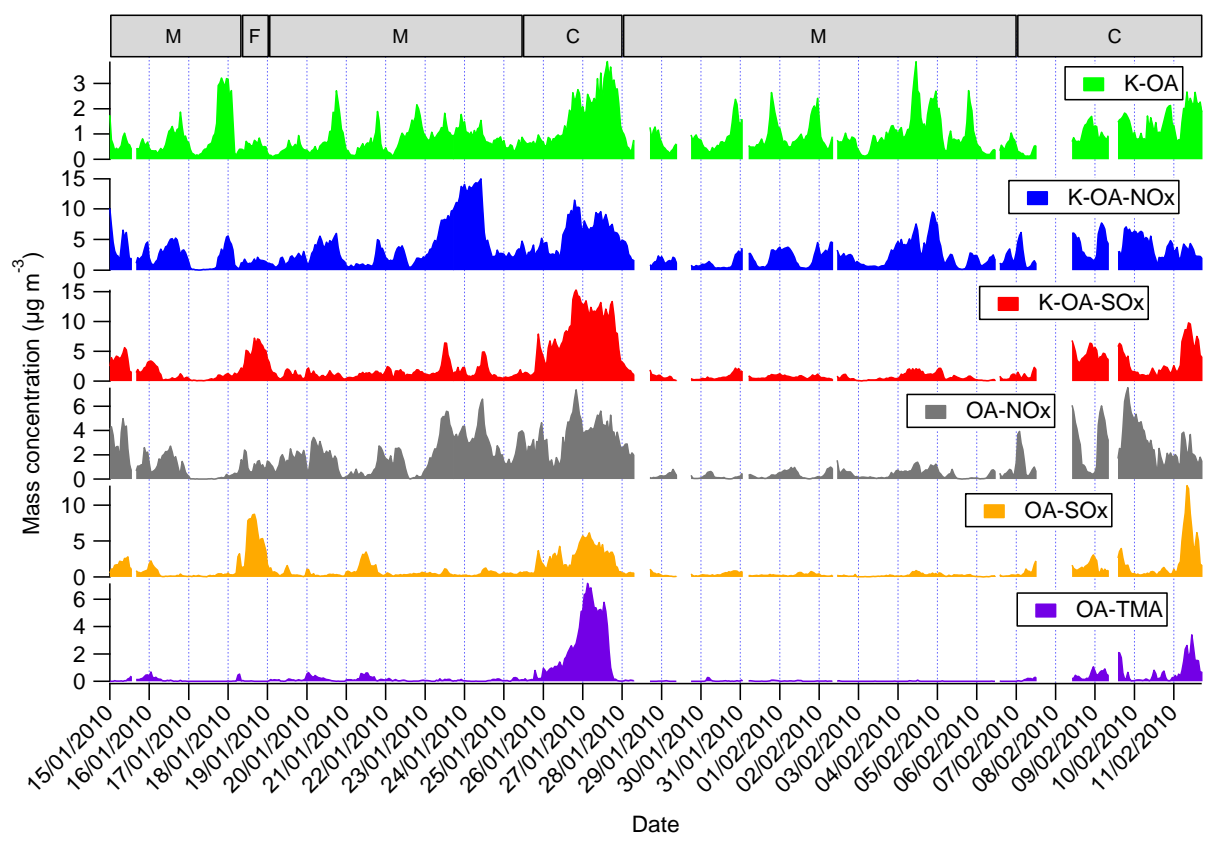

Fig S8. Temporal trends for the estimated mass concentrations of the ATOFMS OA particle classes. $\mathrm{M}, \mathrm{C}$ and $\mathrm{F}$ correspond to periods influenced by marine air masses, continental air masses and fog, respectively. 


\section{S5: Source Apportionment using ATOFMS data}
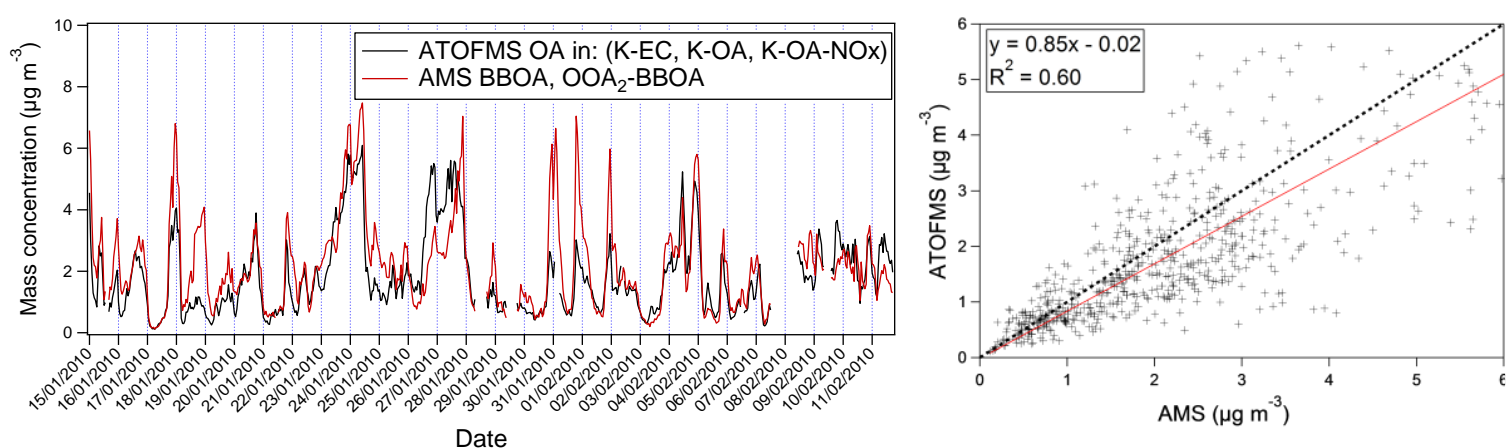

Fig. S9: Comparison of the summed mass concentration of the HR-ToF-AMS BBOA and $\mathrm{OOA}_{2}$ BBOA PMF factors with estimated summed OA content from the ATOFMS K-EC, K-OA and K-OA-NOx single particle classes. The red line represents the orthogonal distance regression fit and the black dashed line represents the 1:1 ratio.

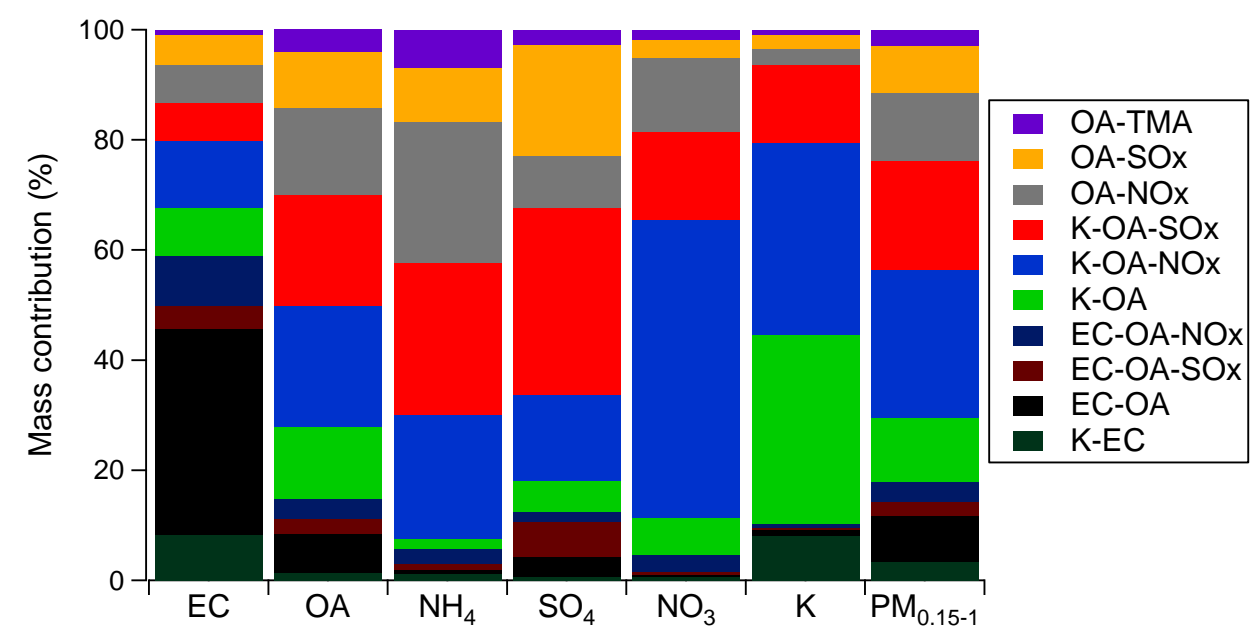

Fig. S10. Estimated relative mass contributions (\%) of each ATOFMS class to each chemical species and total reconstructed mass. 
Table S4. Estimated relative mass contributions (\%) of each ATOFMS class to each chemical species and total reconstructed mass.

\begin{tabular}{|c|c|c|c|c|c|c|c|}
\hline ATOFMS class & $\mathrm{EC}$ & $\mathrm{OA}$ & $\mathrm{NH}_{4}$ & $\mathrm{SO}_{4}$ & $\mathrm{NO}_{3}$ & K & $\mathrm{PM}_{0.15-1}$ \\
\hline K-EC & 8 & 1 & 1 & 1 & 1 & 8 & 3 \\
\hline EC-OA & 37 & 7 & 1 & 4 & 0 & 1 & 8 \\
\hline EC-OA-SOx & 4 & 3 & 1 & 6 & 0 & 0 & 3 \\
\hline EC-OA-NOx & 9 & 4 & 3 & 2 & 3 & 1 & 3 \\
\hline $\mathrm{K}-\mathrm{OA}$ & 9 & 13 & 2 & 6 & 7 & 34 & 12 \\
\hline K-OA-NOx & 12 & 22 & 22 & 16 & 54 & 35 & 27 \\
\hline K-OA-SOx & 7 & 20 & 28 & 34 & 16 & 14 & 20 \\
\hline OA-NOx & 7 & 16 & 26 & 10 & 14 & 3 & 12 \\
\hline OA-SOx & 5 & 10 & 10 & 20 & 3 & 2 & 9 \\
\hline OA-TMA & 1 & 4 & 7 & 3 & 2 & 1 & 3 \\
\hline
\end{tabular}




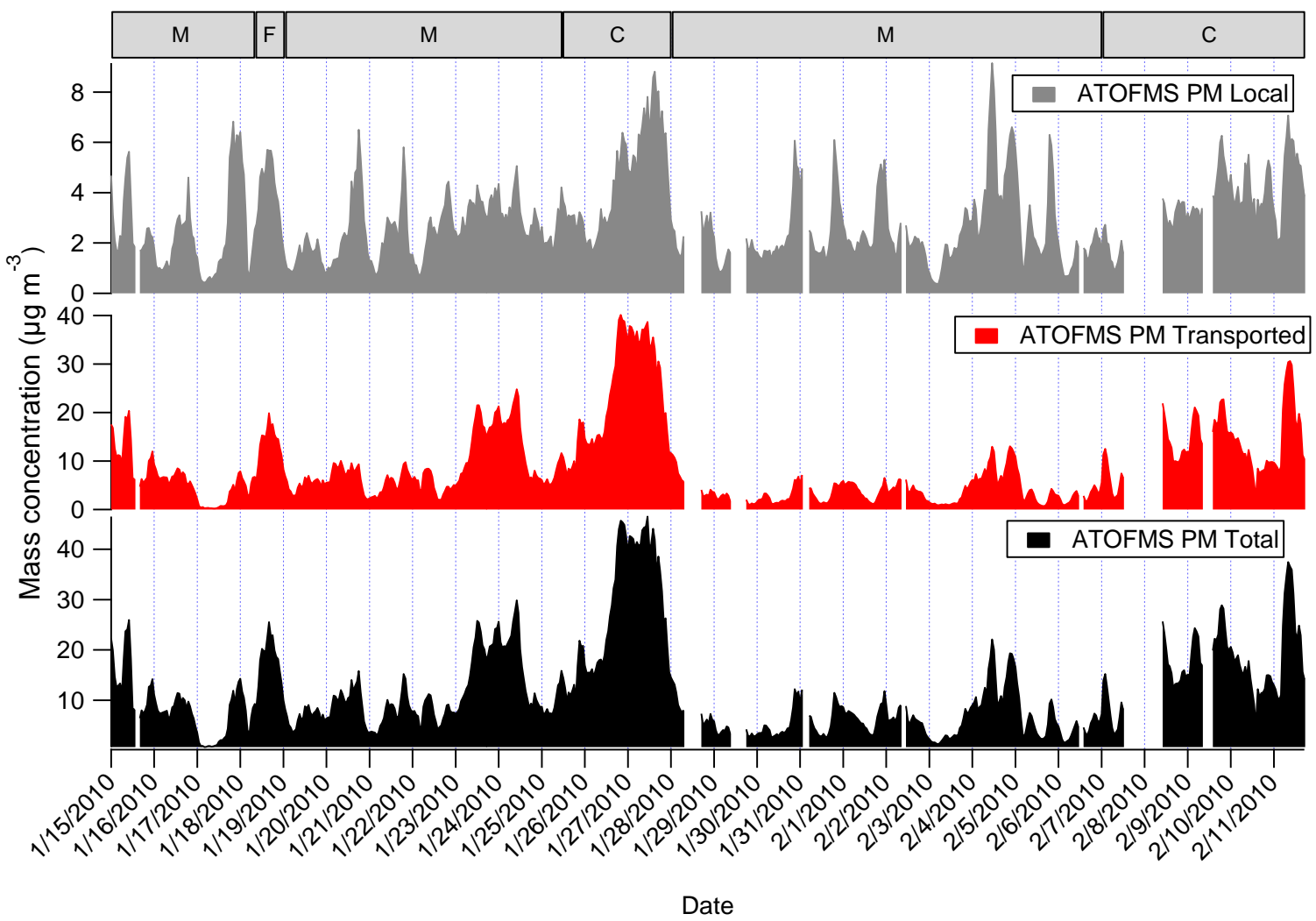

Fig S11. Temporal trends for ATOFMS-derived particle mass apportioned to local and transported sources. M, C and F correspond to periods influenced by marine air masses, continental air masses and fog, respectively. 

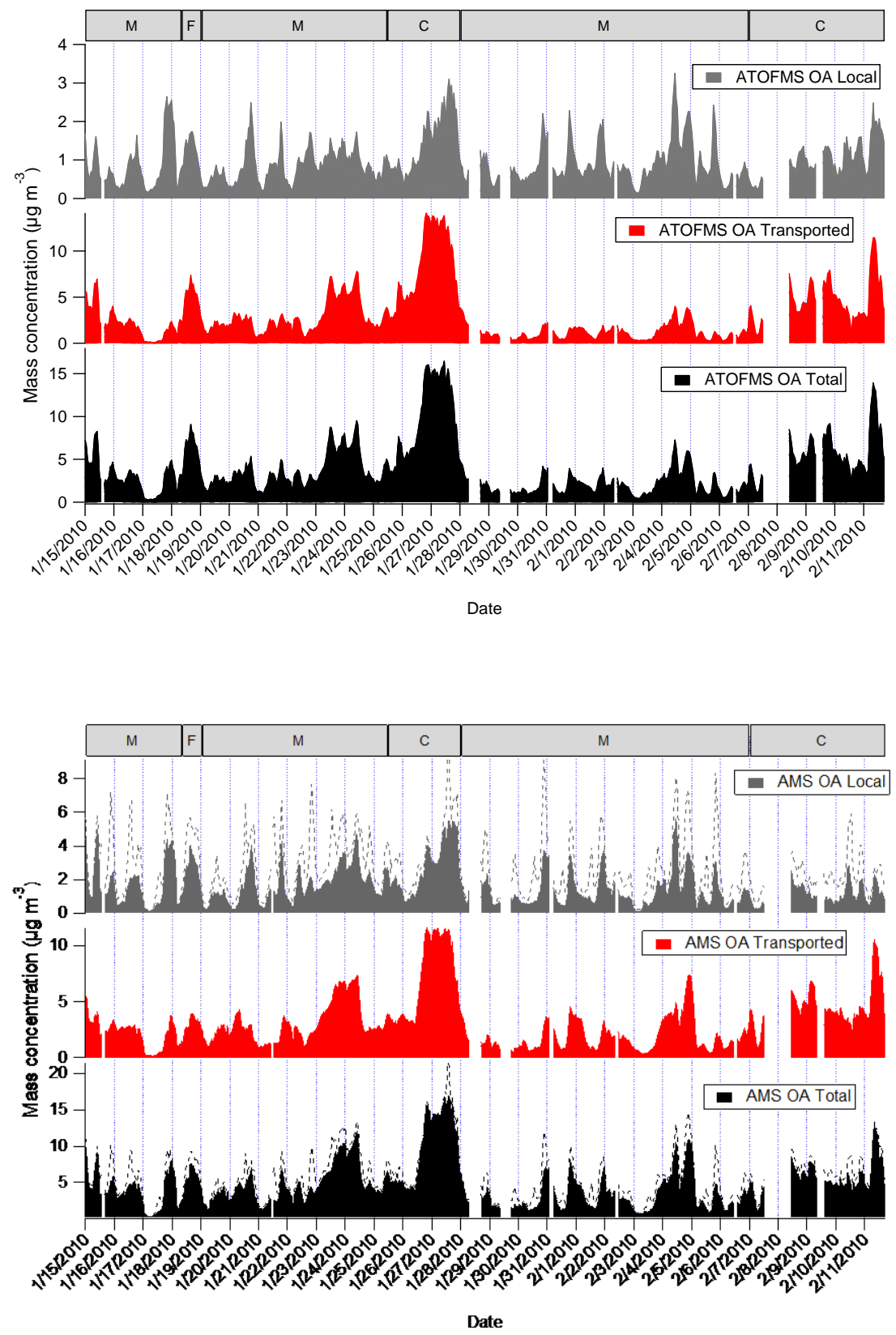

Fig S12. Top: Temporal trends for ATOFMS-derived OA mass concentrations apportioned to local and transported sources. Bottom: Temporal trends for AMS OA factors apportioned to local (HOA, BBOA) and transported sources (BBOA_2, OOA). Dashed lines indicate the contribution of cooking organic aerosol (COA) which was not detected in the ATOFMS dataset. If COA is excluded, the local contribution to OA is estimated to be $33 \%$. If COA is included the local contribution to OA is estimated to be $47 \%$. 


\section{References}

Angelino, S., Suess, D. T., and Prather, K. A.: Formation of Aerosol Particles from Reactions of Secondary and Tertiary Alkylamines: Characterization by Aerosol Time-of-Flight Mass Spectrometry, Environmental Science and Technology, 35, 3130-3138, doi:10.1021/es0015444, 2001.

Bente, M., Sklorz, M., Streibel, T., and Zimmermann, R.: Online Laser DesorptionMultiphoton Postionization Mass Spectrometry of Individual Aerosol Particles: Molecular Source Indicators for Particles Emitted from Different Traffic-Related and Wood Combustion Sources, Analytical Chemistry, 80, 8991-9004, 10.1021/ac801295f, 2008.

Bressi, M., Sciare, J., Ghersi, V., Bonnaire, N., Nicolas, J. B., Petit, J. E., Moukhtar, S., Rosso, A., Mihalopoulos, N., and Féron, A.: A one-year comprehensive chemical characterisation of fine aerosol (PM2.5) at urban, suburban and rural background sites in the region of Paris (France), Atmos. Chem. Phys. Discuss., 12, 29391-29442, 10.5194/acpd-12-29391-2012, 2012.

Cahill, J. F., Suski, K., Seinfeld, J. H., Zaveri, R. A., and Prather, K. A.: The mixing state of carbonaceous aerosol particles in northern and southern California measured during CARES and CalNex 2010, Atmos. Chem. Phys., 12, 10989-11002, 10.5194/acp-1210989-2012, 2012.

Crippa, M., DeCarlo, P. F., Slowik, J. G., Mohr, C., Heringa, M. F., Chirico, R., Poulain, L., Freutel, F., Sciare, J., Cozic, J., Di Marco, C. F., Elsasser, M., José, N., Marchand, N., Abidi, E., Wiedensohler, A., Drewnick, F., Schneider, J., Borrmann, S., Nemitz, E., Zimmermann, R., Jaffrezo, J. L., Prévôt, A. S. H., and Baltensperger, U.: Wintertime aerosol chemical composition and source apportionment of the organic fraction in the 
metropolitan area of Paris, Atmos. Chem. Phys., 13, 961-981, 10.5194/acp-13-961-981, 2013

Harrison, R. M., Beddows, D. C. S., Hu, L., and Yin, J.: Comparison of methods for evaluation of wood smoke and estimation of UK ambient concentrations, Atmos. Chem. Phys., 12, 8271-8283, 10.5194/acp-12-8271-2012, 2012.

Healy, R. M., Hellebust, S., Kourtchev, I., Allanic, A., O'Connor, I. P., Bell, J. M., Healy, D. A., Sodeau, J. R., and Wenger, J. C.: Source apportionment of PM2.5 in Cork Harbour, Ireland using a combination of single particle mass spectrometry and quantitative semicontinuous measurements, Atmos. Chem. Phys., 10, 9593-9613, 10.5194/acp-10-95932010, 2010.

Healy, R. M., Sciare, J., Poulain, L., Kamili, K., Merkel, M., Müller, T., Wiedensohler, A., Eckhardt, S., Stohl, A., Sarda-Estève, R., McGillicuddy, E., O'Connor, I. P., Sodeau, J. R., and Wenger, J. C.: Sources and mixing state of size-resolved elemental carbon particles in a European megacity: Paris, Atmos. Chem. Phys., 12, 1681-1700, 10.5194/acp-12-1681-2012, 2012.

McGuire, M. L., Jeong, C. H., Slowik, J. G., Chang, R. Y. W., Corbin, J. C., Lu, G., Mihele, C., Rehbein, P. J. G., Sills, D. M. L., Abbatt, J. P. D., Brook, J. R., and Evans, G. J.: Elucidating determinants of aerosol composition through particle-type-based receptor modeling, Atmos. Chem. Phys., 11, 8133-8155, 10.5194/acp-11-8133-2011, 2011.

Moffet, R. C., de Foy, B., Molina, L. T., Molina, M. J., and Prather, K. A.: Measurement of ambient aerosols in northern Mexico City by single particle mass spectrometry, Atmos. Chem. Phys., 8, 4499-4516, 2008.

Pagels, J., Dutcher, D. D., Stolzenburg, M. R., McMurry, P. H., Gälli, M. E., and Gross, D. S.: Fine-particle emissions from solid biofuel combustion studied with single-particle 
mass spectrometry: Identification of markers for organics, soot, and ash components, Journal of Geophysical Research: Atmospheres, n/a-n/a, 10.1029/2012jd018389, 2013.

Pratt, K. A., Hatch, L. E., and Prather, K. A.: Seasonal Volatility Dependence of Ambient Particle Phase Amines, Environmental Science \& Technology, 43, 5276-5281, 10.1021/es803189n, 2009.

Pratt, K. A., and Prather, K. A.: Real-Time, Single-Particle Volatility, Size, and Chemical Composition Measurements of Aged Urban Aerosols, Environmental Science \& Technology, 43, 8276-8282, 10.1021/es902002t, 2009.

Pratt, K. A., Murphy, S. M., Subramanian, R., DeMott, P. J., Kok, G. L., Campos, T., Rogers, D. C., Prenni, A. J., Heymsfield, A. J., Seinfeld, J. H., and Prather, K. A.: Flight-based chemical characterization of biomass burning aerosols within two prescribed burn smoke plumes, Atmos. Chem. Phys., 11, 12549-12565, 10.5194/acp-11-12549-2011, 2011.

Qin, X., Pratt, K. A., Shields, L. G., Toner, S. M., and Prather, K. A.: Seasonal comparisons of single-particle chemical mixing state in Riverside, CA, Atmospheric Environment, 59, 587-596, 10.1016/j.atmosenv.2012.05.032, 2012.

Rehbein, P. J. G., Jeong, C.-H., McGuire, M. L., Yao, X., Corbin, J. C., and Evans, G. J.: Cloud and Fog Processing Enhanced Gas-to-Particle Partitioning of Trimethylamine, Environmental Science \& Technology, 45, 4346-4352, 10.1021/es1042113, 2011.

Silva, P. J., Liu, D. Y., Noble, C. A., and Prather, K. A.: Size and chemical characterization of individual particles resulting from biomass burning of local Southern California species, Environmental Science \& Technology, 33, 3068-3076, 1999. 